\title{
Military Diet on the Border: Butchery Analysis at Fort Brown (41DF96) Cameron County, Texas
}

Crystal A. Dozier

Department of Anthropology, Texas A\&M University

Follow this and additional works at: https://scholarworks.sfasu.edu/ita

Part of the American Material Culture Commons, Archaeological Anthropology Commons, Environmental Studies Commons, Other American Studies Commons, Other Arts and Humanities Commons, Other History of Art, Architecture, and Archaeology Commons, and the United States History Commons

Tell us how this article helped you.

This Article is brought to you for free and open access by the Center for Regional Heritage Research at SFA ScholarWorks. It has been accepted for inclusion in Index of Texas Archaeology: Open Access Gray Literature from the Lone Star State by an authorized editor of SFA ScholarWorks. For more information, please contact cdsscholarworks@sfasu.edu. 


\section{Military Diet on the Border: Butchery Analysis at Fort Brown (41DF96) Cameron County, Texas}

\section{Licensing Statement}

Reproduction, posting, transmission, or other distribution or use of the Journal volume, individual article or any portion of the material therein, in any medium, is permitted strictly for personal, non-commercial purposes via a personal-use exemption under a Creative Commons license granted by JTAH.org, Inc. This license exemption requires, as a condition of its granted permission, proper credit be attributed to JTAH.org as copyright holder (e.g., Journal of Texas Archeology and History.org @ 2017). No part of this publication may be reproduced, posted, transmitted, or otherwise utilized or distributed in any form by any means or method for commercial purposes without the express written consent of the Publisher. Inquiries should be addressed to JTAH Publisher, Suite 307, Box 361, 5114 Balcones Woods Drive, Austin, Texas, 78759.

The Journal of Texas Archeology and History.org is an organization dedicated to furthering research, education and public outreach in the fields of archeology and history concerning Texas and its bordering states of Louisiana, Arkansas, Oklahoma, New Mexico and Northern Mexico; a region we call the "Texas Borderlands." The J.T.A.H. is collaborating with the Index of Texas Archaeology and S.F.A.S.U. to distribute their publication library to the general public via free and open-access channels. Visit www.JTAH.org to submit an article. 


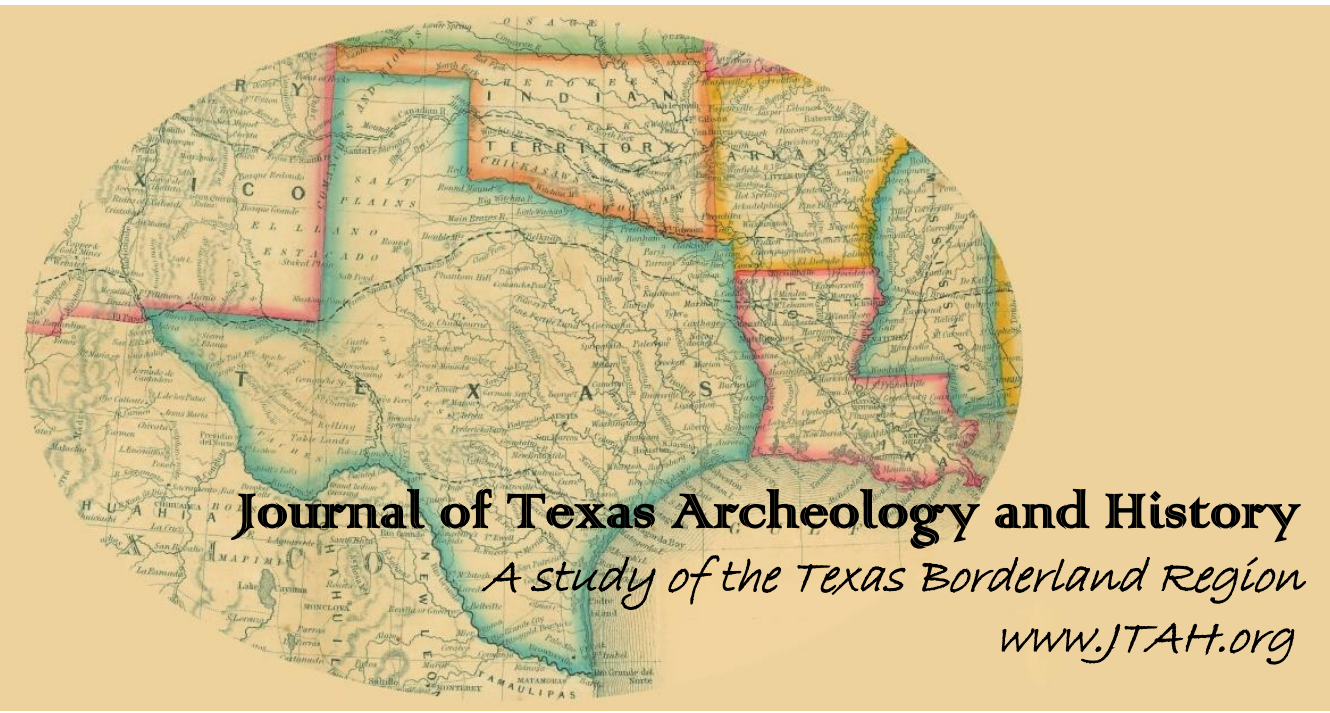

\section{Article Title: MILITARY DIET ON THE BORDER: BUTCHERY ANALYSIS AT FORT BROWN (41CF96) CAMERON COUNTY, TEXAS}

\section{Author(s): $\quad$ Crystal A. Dozier}

Original Source: J.T.A.H. Volume 3 (2016/2017), Article 4, pp. 97 - 116; online 17 July 2017

Recommended Citation: Dozier, Crystal A.; "Military Diet on the Border: Butchery Analysis at Fort Brown (41DF96) Cameron County, Texas", (2017), Journal of Texas Archeology and History Volume 3 (2016/2017), pp. 97 - 116.

Copyright $(C 2017$ by Journal of Texas Archeology and History.org, Inc. All rights reserved. Online/Digital publication: ISSN 2334-1874

The online, digital, and print versions of the publication "Journal of Texas Archeology and History" are published by Journal of Texas Archeology and History.org, Inc., a Texas nonprofit IRC Section 501(c)(3) corporation.

Reproduction, posting, transmission, or other distribution or use of the Journal volume, individual article or any portion of the material therein, in any medium, is permitted strictly for personal, non-commercial purposes via a personal-use exemption under a Creative Commons license granted by JTAH.org, Inc. This license exemption requires, as a condition of its granted permission, proper credit be attributed to JTAH.org as copyright holder (e.g., Journal of Texas Archeology and History.org (c) 2017). No part of this publication may be reproduced, posted, transmitted, or otherwise utilized or distributed in any form by any means or method for commercial purposes without the express written consent of the Publisher. Inquiries should be addressed to JTAH Publisher, Suite 307, Box 361, 5114 Balcones Woods Drive, Austin, Texas, 78759.

The Journal of Texas Archeology and History.org is an organization dedicated to furthering research, education and public outreach in the fields of archeology and history concerning Texas and its bordering states of Louisiana, Arkansas, Oklahoma, New Mexico and Northern Mexico; a region we call the "Texas Borderlands." The J.T.A.H. is collaborating with the Index of Texas Archaeology and S.F.A.S.U. to distribute their publication library to the general public via free and open-access channels. Visit www.JTAH.org to submit an article. 


\title{
MILITARY DIET ON THE BORDER: BUTCHERY ANALYSIS AT FORT BROWN (41CF96) CAMERON COUNTY, TEXAS
}

\author{
Crystal A. Dozier \\ Department of Anthropology \\ Texas A\&M University
}

\begin{abstract}
Archaeological investigations at Fort Brown (41CF96) have provided a wealth of information about military life in south Texas. This re-analysis of the faunal material recovered by the Archaeological Research Laboratory's survey efforts in 1988 investigates butchering patterns found at the site. While evidence for modern European American cuts are present, processing of beef os coxae and sacrum are inconsistent with current European American butchery practices. The assemblage is dominated by inexpensive cuts of meat that would have allowed for easy cooking within stews or soups. The butchery patterns seen at Fort Brown are compared to early twentieth century military standards as well as local, and particularly Mexican, influences on Fort Brown foodways.
\end{abstract}

\section{INTRODUCTION}

Fort Brown is located on the Rio Grande in Cameron County, Texas, between the twin cities of Brownsville, Texas and Matamoros, Tamaulipas, Mexico. Fort Brown was founded in 1846 and was occupied by various companies of the US Army from 1865 to 1906 and again from 1914 to 1944. The city of Brownsville was the civilian support for Fort Brown and has supported a diverse population of Tejano, Mexican, and European American peoples since its founding concurrent with Fort Brown. The Fort was temporarily relinquished to the Department of the Interior as an experimental garden for spineless varieties of cacti in 1906 after the "Brownsville Incident", when a white bartender was shot and the African American regiment stationed at Fort Brown were falsely accused, resulting in the dishonorable discharge of 167 enlisted men (Christian 1989). With the U.S. entrance into World War I looming and tensions with Mexico mounting, in 1914 the Fort was reinstated for military use by the Department of War; by 1916, 10 different companies of infantry and cavalry were garrisoned at Fort Brown. Hurricanes in 1919 and 1930 caused massive destruction and reconstruction in both Fort Brown and Brownsville. The Fort was deactivated in 1945, after which the Army deeded and sold the Fort grounds to the City of Brownsville and Texas Southmost College (Marcum 1964; Sides 1942).

A considerable amount has been published on the military movements and occupations of Fort Brown (Davenport 2010; Marcum 1964; Sides 1942), yet relatively little has been published about the

\footnotetext{
JOURNAL OF TEXAS ARCHEOLOGY AND HISTORY

VOLUME 3:97-116

THE ONLINE PUBLICATION JOURNAL OF TEXAS ARCHEOLOGY AND HISTORY (ISSN 2334-1874)

IS PUBLISHED BY JOURNAL OF TEXAS ARCHEOLOGY AND HISTORY.ORG. COPYRIGHT (c) 2017 JOURNAL OF TEXAS ARCHEOLOGY AND HISTORY.ORG. ALL RIGHTS RESERVED.
} 
lived experience of the individuals on this true border post. Two primary histories highlight the Fort and its military activities, but no mention is made of how rations were prepared or distributed.

Within historical archaeology, faunal analysis has been utilized in efforts to talk about meat consumption, diet breadth, ethnic backgrounds, and class divisions. In these approaches, diet reflects the positionality of the consumers (Reitz 1987; Huelsbeck 1991); therefore, differences in ethnic identity, class, and wealth are expected to be reflected in dietary choices. Zooarchaeological methodologies through the past several decades have developed in complexity to address questions of how meat consumption reflects social identities and inequalities (Crabtree 1985, 1990; Jolley 1983; Landon 2005, 2009). Recent studies have accessed how diet breadth and butchering patterns differed between indigenous and immigrant populations (Seetah 2006a; Seetah et al. 2014) and different ethnic populations within cities (Gifford-Gonzalez 1991; Landon 1996). As Fort Brown and Brownsville were home to a diverse set of military and local peoples, foodways should also reflect those influences.

To better understand how patterns of meat preparation and consumption reflect upon social aspects (Dawdy 2010) of Fort Brown life the zooarchaeological evidence of butchering at Fort Brown is analyzed, with attention to the cuts of meat, especially beef. As no published histories relate meat acquisition and consumption from Fort Brown, I compare the archaeological evidence to published military guidelines for meat preparation (Deitrick 1917; Rees 1998) and consider the local, Mexicaninfluenced butchery practices in Brownsville (Chatfield 1893). I explore the butchery techniques, dietary choices, and socio-economic implications inherent in meat consumption choices from this unique military outpost.

\section{MATERIALS AND METHODS}

In 1988, the Texas A\&M University Archeological Research Laboratory (ARL) conducted archaeological investigations at Fort Brown as new classrooms were constructed at Texas Southmost College. Despite a rushed excavation schedule, ARL recovered almost 14,000 artifacts though trenching and excavation test units (Carlson et al. 1990). Brian Shaffer (1990) conducted the only faunal investigation of the Fort Brown excavations. Shaffer analyzed over 1,500 faunal remains, and was able to identify $12 \%$ of the vertebrate fauna to the family level. His analysis was only presented in aggregate form and the complete record of his analysis was electronically saved on a program that no longer exists. Shaffer's thorough analysis identified a variety of mammals, birds, canines, and many non-domesticated fauna species. Shaffer recorded the presence of butchery marks on individual specimens, but he did not record the types and patterns of the marks. To better understand the butchery patterns at Fort Brown, I analyzed a subset of what Shaffer reported and only recorded specimens that showed evidence of butchering.

Each individual specimen from the entire faunal assemblage housed at ARL was examined for butchering evidence, a total of a total of 132 specimens. Shaffer identified 183 butchered specimens; he identified some butchered taxa that I did not encounter but would have likely recognized (such as bird bones). Shaffer provided a table of excavation unit data, but none of the artifact bags I received had the proveniences he indicated. As such, the box(es) containing the faunal remains from the 
excavation units must not be housed with the rest of the zooarchaeological materials and were not examined.

To understand the butchering patterns made at Fort Brown, Lyman's (1977) methodology was adopted and each of the 132 specimens showing evidence for butchering (out of the 1,500 that Shaffer examined) were coded for faunal element, element features, side, taxa identification, and information about the type of butchery marks. Following Lyman (1977), I made complete drawings of specimens and their respective butchery marks for specimens identifiable to element and taxa. The full data set can be accessed online here and the drawings of butchered elements can be accessed here. For this analysis, identification of faunal element and taxa was extremely important; therefore, the comparative collection at Texas A\&M University was consulted, and the University of Nebraska's Beef and Pork Myology websites were accessed for cross-sectional views.

Zooarchaeological studies have long demonstrated the importance of distinguishing the type of implement/tool used to create butchering marks (Bunn and Kroll 1986; Domínguez-Rodrigo et al. 2009, 2010; Greenfield 2006; Lyman 1987a; Rixson 1989; Seetah 2006b, 2006a, 2008). Butchering marks were quite evident in this collection as many bones retained clear striations from saw teeth and/or clean, straight edges indicative of removal with a non-teethed metal knife, such as a cleaver. Forensic studies have shown that saw marks are regularly identifiable to type of saw (Andahl 1978), although not to an individual saw (Freas 2010; Saville et al. 2007). Saw marks are identifiable as the motion of the saw and the arrangement of teeth are impressed within the cutting surface (called the kerf). Distinctions were made between hand saw (which show linear, but non-regular, marks), electric saw (which show regular, parallel linear marks), and chop marks (where cut marks show directionality without striations caused by teeth). The opportunities for this methodology of distinguishing between hand and electric saws to inform upon archaeological questions are just now being applied (Dasovich and Vollman 2017). Figure 1 showcases examples of the three types of identification made.

Cancellous (trabecular) bone generally does not preserve saw tooth marks as well as cortical bone; some specimens were able to be identified as sawn but some were not. Using a cleaver to hack through vertebrae is an extremely common butchery practice (Seetah 2008), which leaves sometimes indeterminate marks on the bone; this indeterminacy was acknowledged in the coding scheme. Degradation of bone also hindered identification; cases where the specimen was too degraded or kerf features were indeterminate as to the type of tool used were labeled as unknown. Inspection of the collection revealed a variety of fresh breaks and marks consistent with recent excavation. To reduce conflation of excavation-marks and butchery practice in the absence of microscopic analysis, small $(<1 \mathrm{~cm})$ cut marks were not recorded.

As the drawings indicate, 40 specimens were sawn or hacked on opposing sides of the element, like slices of bread, so I refer to such as slicing. I recorded the thickness of the cut for sliced specimens using a digital caliper. Three specimens showed a false start, where an electric blade started to cut but was removed and repositioned to make a final cut, as shown in Figure 2; the width of the false start was measured with a digital caliper to estimate the blade's thickness. 


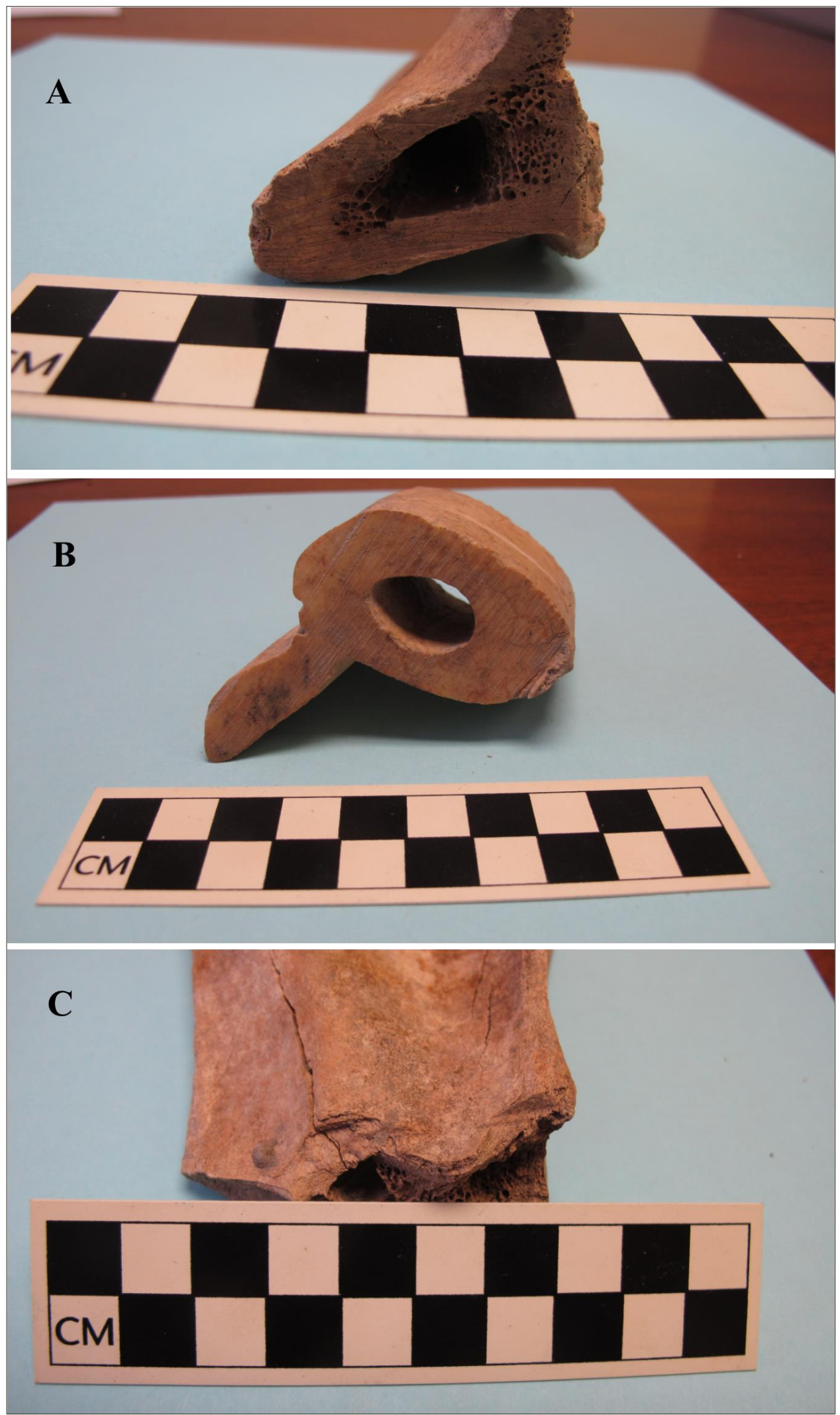

Figure 1. Examples of butchering marks. A. Hand saw. B. Electric/machine saw. C. Chop marks. 

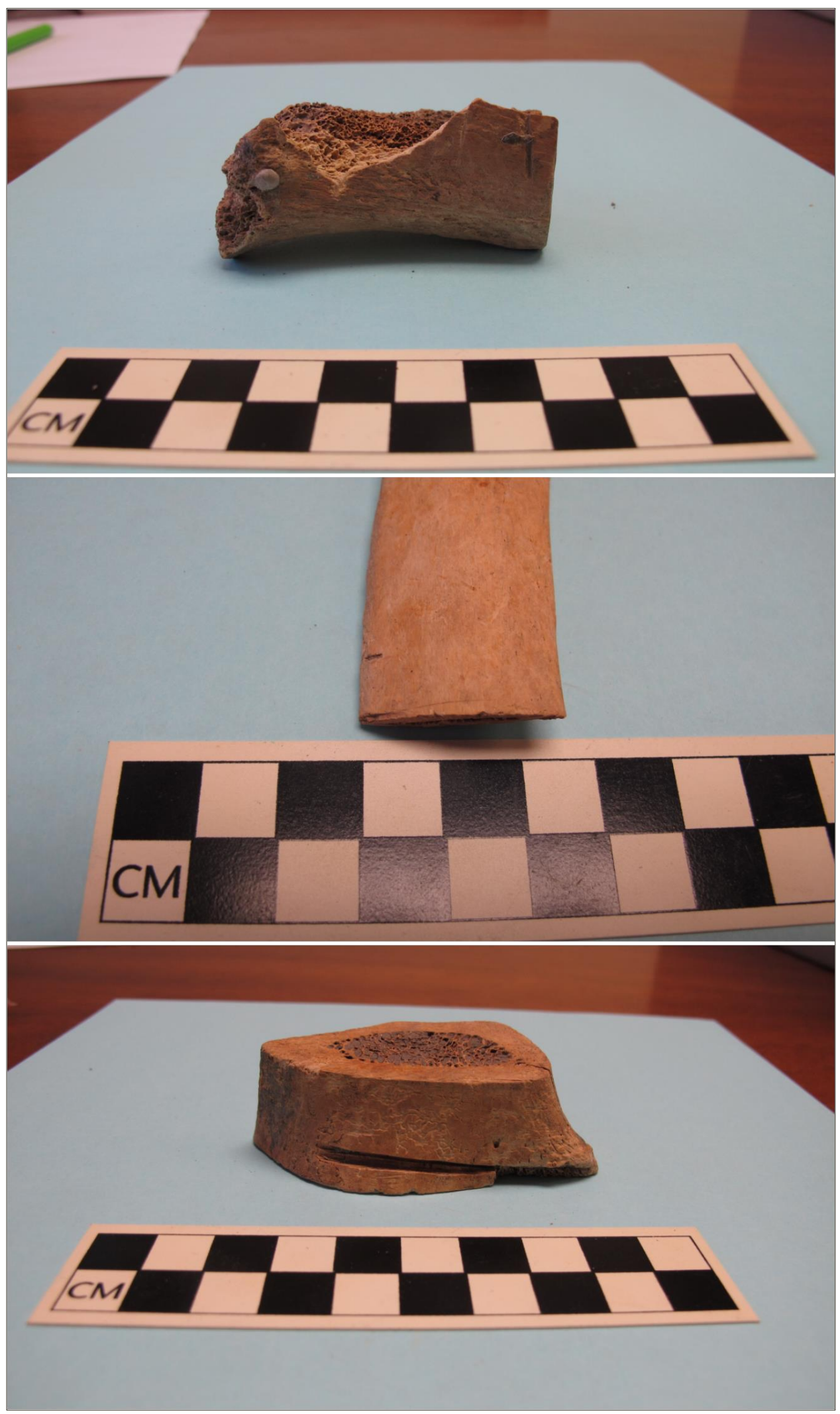

Figure 2. Machine sawing false starts. 
Following Lyman (1987b), I use historical sources (Chatfield 1893; Deitrick 1917) to compare the butchering patterns and relative cost of different cuts of meat. Exact cuts of meat at Fort Brown are unknown, I only made distinctions between more universal cuts. For beef, the following distinctions were made according to what aspect of each element was present: sirloin, short loin, round, rib, chuck, and shank. Of course, much meat can be removed from these sections without leaving the bones, but such distinctions are still useful to understand what cuts are made.

\section{Context, Taphonomy, and Historical Documentation}

None of the identified archaeological features from the 1988 Fort Brown archaeological excavations suggest a context or feature only associated with butchery, food preparation, or consumption. Therefore, detailed reconstruction of individual meal types or dishes are impossible, although general patterns in diet may be accessed. It is unclear if the faunal remains are from meal preparation or meal consumption. With advancements in bone taphonomy to distinguish between cooked and uncooked bone (Koon et al. 2010), it may be one day possible to determine if these remains had been part of consumed meals. The faunal remains within this collection likely were deposited differentially and perhaps from different periods of the Fort's occupation.

Within the limited sample $(\mathrm{N}=132)$, it is possible that different butchery practices are represented, but the resolution of the assemblage will not allow for such evaluations. Issues of differential taphonomy and preservation are confounding variables. Because this was a salvage excavation, full description of the site was impossible. Prior to 1988, no archaeological work or preservation had been done at Fort Brown and it is difficult to say if some areas of the site may have been more affected by taphonomic processes than others (Carlson et al. 1990). For the purposes of this analysis, I have assumed that taphonomic processes have not differentially affected the assemblage.

\section{RESULTS}

\section{Taxa}

As presented in Figure 3 and Table 1, a majority of the assemblage could not be assigned to taxa; 70 specimens were assigned to either mammal (of indeterminate size), large mammal (such as horse, cattle, or large pig), medium mammal (such as goats or deer), or small mammal (such as dogs, cats, or smaller). Forty-two percent of the assemblage could be determined as belonging to the genus Bos. I adhere to Shaffer's (1990) terminology; most skeletal elements cannot be distinguished between Bison bison (American bison) and Bos taurus (domesticated cattle), though the historicity of the site (as well as its geography) very strongly indicates that these specimens are domesticated cattle. Nonetheless, in this text I shall keep to the terminology of Bos in efforts for consistency with previous publication. All taxa recorded in my sample have a minimum number of individuals (MNI) of 1; Shaffer (1990:143) calculated an MNI of two from the assemblage in its entirety for Bos. However, due to the diverse archaeological contexts in which elements were recovered, it is highly unlikely that a single animal is responsible for the multitude of meals reflected in the assemblage. Very few other taxa were observed among the butchered assemblage. Four specimens belonging to Sus scrofa (domesticated 
pig) were observed, as well as a single vertebra from the genus Odocoileus (deer) and a single radius that cannot be distinguished between Ovis (sheep) and Capra (goat).

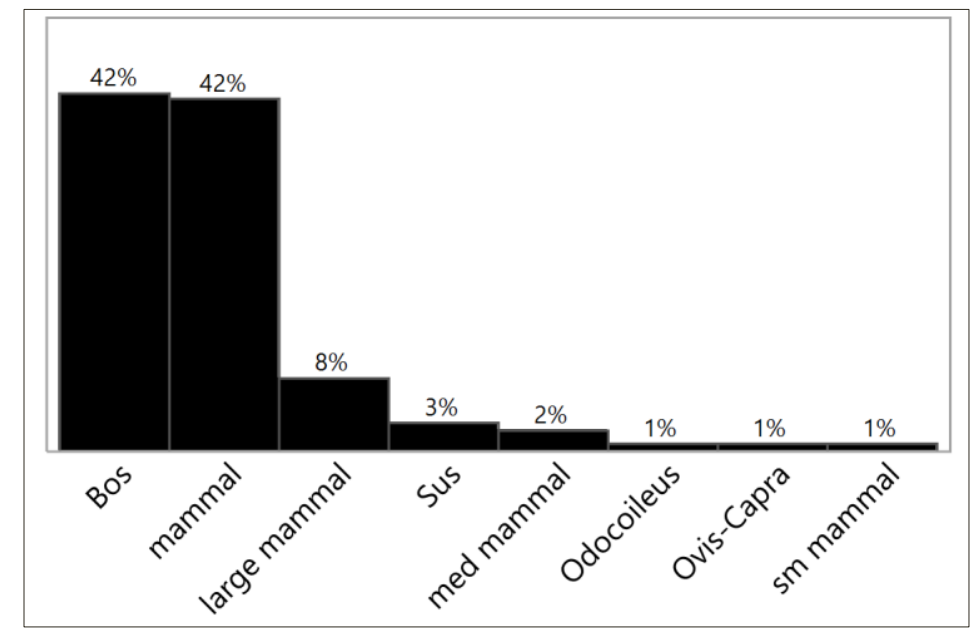

Figure 3. Distribution of butchered taxa. $\mathrm{N}=132$.

Table 1. Butchered elements by taxa.

\begin{tabular}{ll}
\hline Taxa & N \\
\hline Mammal & 55 \\
Large Mammal & 11 \\
Medium Mammal & 3 \\
Small Mammal & 1 \\
Bos & 56 \\
Sus & 4 \\
Odocoileus & 1 \\
Ovis-Capra & 1 \\
& Total: 132 \\
\hline
\end{tabular}

\section{Element}

As shown in Figure 4, a third of the specimens $(n=43)$ in the butchered assemblage could not be assigned to element. Ribs made up $14 \%$ of the assemblage, followed by lumbar vertebrae $(10 \%)$, elements of the os coxae (9\%), and indeterminate long bones (9\%). Specimens identified to Bos $(\mathrm{N}=56)$ constituted the majority of the identified elements, shown in Figure 5. Twelve specimens were identified as lumbar vertebrae, $21 \%$ of Bos elements, followed by rib elements $(20 \%)$ and portions of the os coxae (16\%). Table 2 compares the elemental composition of the overall assemblage to the Bos assemblage. 


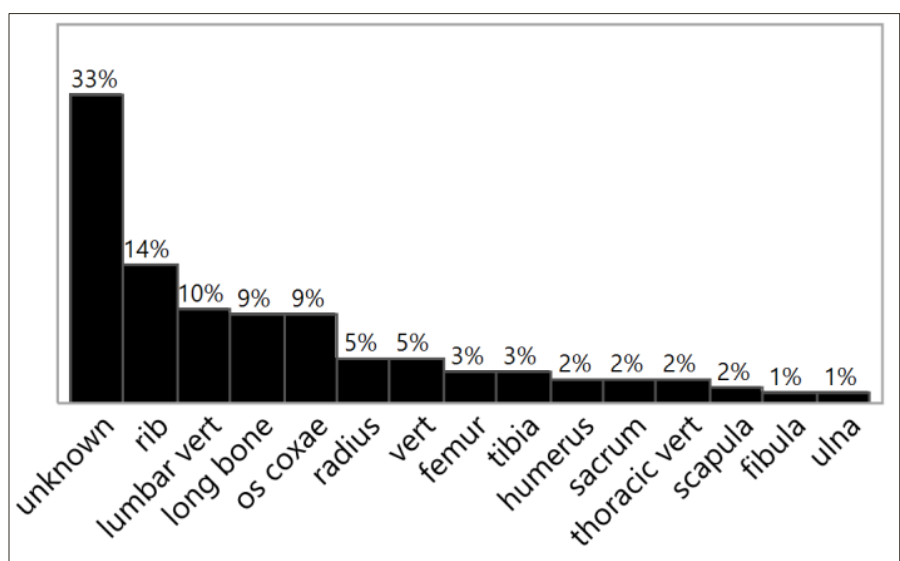

Figure 4. Assemblage by element. $\mathrm{N}=132$.

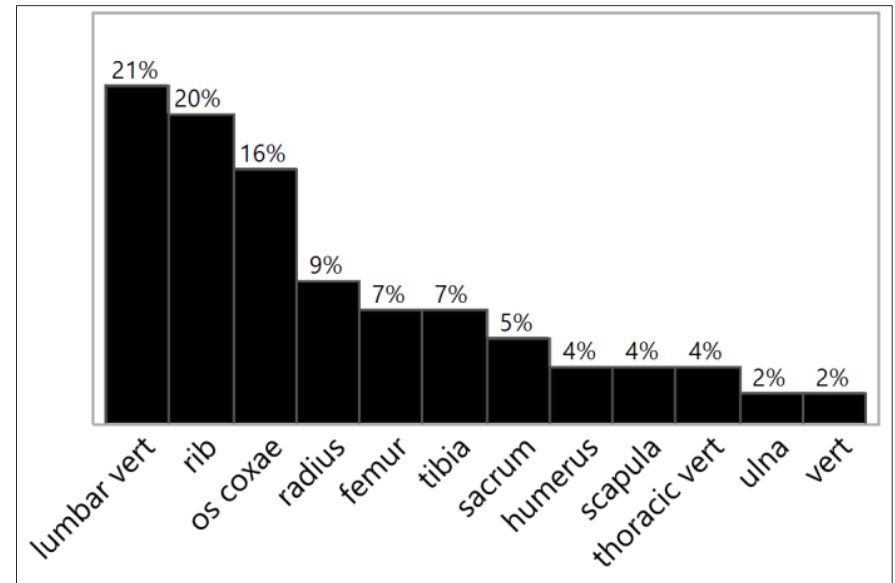

Figure 5. Elements identified as Bos. $N=56$.

Table 2. Comparison of elements in whole butchered assemblage versus Bos assemblage.

\begin{tabular}{lll}
\hline Element & $\mathbf{N}$, assemblage & $\mathbf{N}$, Bos \\
\hline Unknown & 43 & -- \\
Rib & 19 & 11 \\
Lumbar Vertebrae & 13 & 12 \\
Long bone & 12 & -- \\
Ox Coxae & 12 & 9 \\
Radius & 6 & 5 \\
Vertebrae & 6 & 1 \\
Tibia & 4 & 4 \\
Femur & 4 & 4 \\
Humerus & 3 & 2 \\
Sacrum & 3 & 3 \\
Thoracic Vertebrae & 3 & 2 \\
Scapula & 2 & 2 \\
Fibula & 1 & -- \\
Ulna & 1 & 1 \\
& Total: 132 & Total: 56 \\
\hline
\end{tabular}

*Whole assemblage includes Bos elements. All specimens identified as Bos were identified to element. 


\section{Cuts of Meat}

Within the beef assemblage, the assemblage was dominated by the traditionally cheaper cuts of meat: the round (29\%), rib (25\%), and shank (23\%), though more expensive cuts, the sirloin and the short loin make up a sizeable 20\%, as shown in Figure 6.

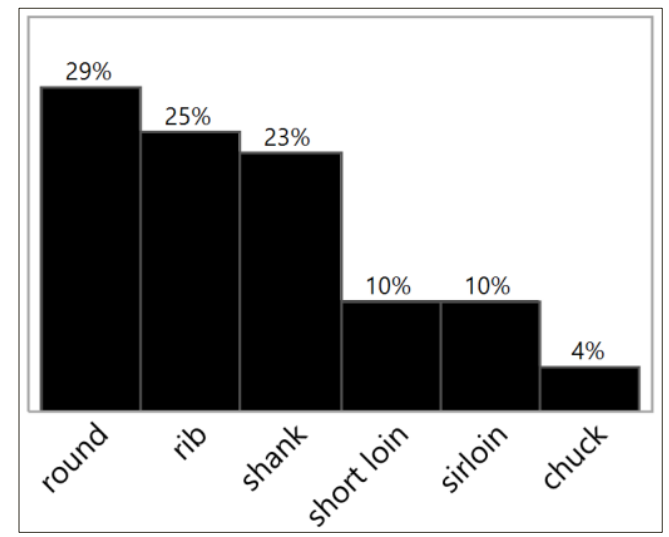

Figure 6 . Identified cuts of beef. $\mathrm{N}=52$.

\section{Type of Saw}

Good preservation of kerf walls in the assemblage made for a fairly high rate of identification, as shown in Figure 7. Electric saw marks are present on nearly half of the identified butchered bones. Chop marks were observed in conjunction with both electric and hand saws, as well as identified by themselves. Only $6 \%$ of the assemblage was sawn by hand, though no patterns emerged of which elements were hand sawn versus electrically sawn.

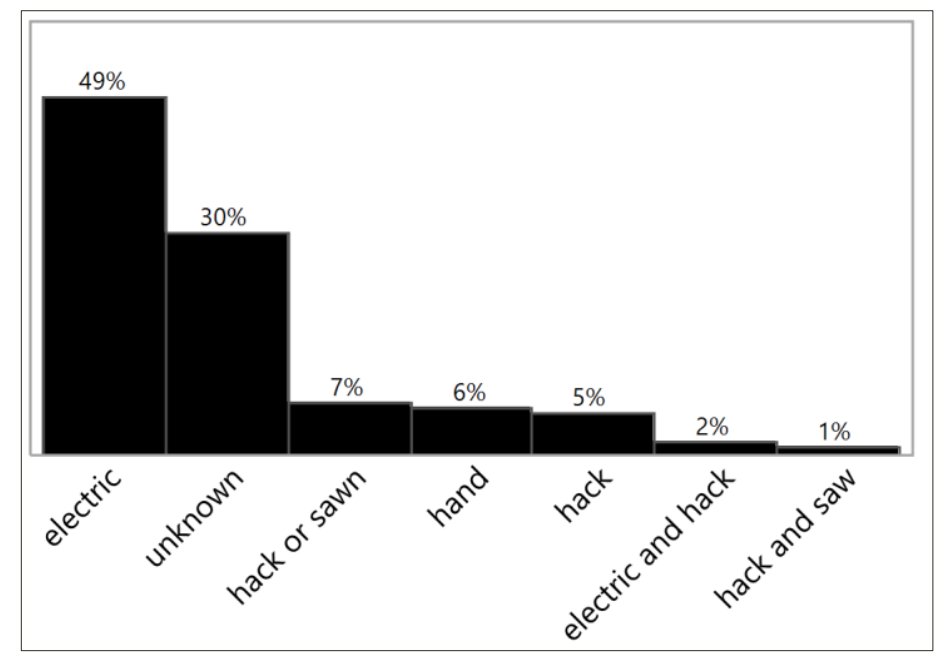

Figure 7. Types of butchering marks. $\mathrm{N}=132$. 


\section{Thickness of Cuts}

Forty specimens, representing just over $30 \%$ of the assemblage, were sawn into slices by removing both proximate and distal portions of the bone; the distribution of the thicknesses are presented in Figure 8. The mean thickness of specimens cut on both sides was $16.6 \mathrm{~mm}$, with a standard deviation of $4.65 \mathrm{~mm}$. Only one outlier was observed at $31 \mathrm{~mm}$. Three false starts were observed with three different kerf widths, which indicate a three different saws (Saville et al. 2007).

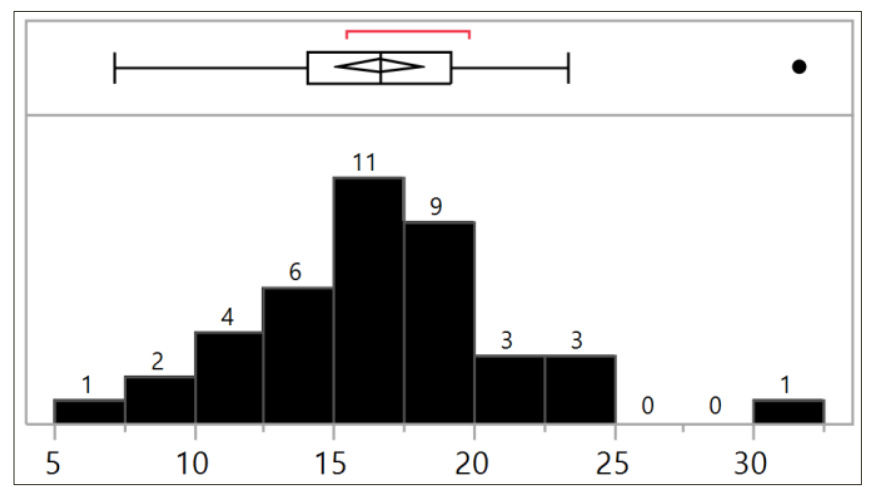

Figure 8. Thickness of sliced specimens, in $\mathrm{mm} . \overline{\mathrm{x}}=16.66, \mathrm{~N}=40$.

\section{Patterns in Butchery}

The distribution of beef skeletal cuts is presented into Figure 9. Vertebrae showed consistency in butchery; similar to modern European American butchery practice, the vertebral elements were split through the body medially to section the carcass into right and left halves. While the vertebral dorsal spine was broken in a majority of the observed elements, a few examples indicate that the spine (often referred to as the "feather bone" by butchers) was sawn off at least for the thoracic vertebrae. In addition to cuts through center of the vertebrae, some of the vertebrae were also cut proximatedistally, often sectioning the vertebrae into two or three slices. Sacral elements were also sawn in a similar manner, although only three specimens were recovered. Similar to the vertebrae, the sacral elements were split medially as well as sliced.

Aspects of the os coxae show consistent patterns in butchery as well. The specimens were cut into slices, many through the arches connecting the ischium and ilium to the acetabulum. Two specimens were cut through the acetabulum. Patterns in the rest of the axial skeleton are elusive due to the smaller number of observed elements. While ribs were clearly sawn into proximal and medial sections, the lack of consistent size and biological markers make the determination if a consistent cut is preferred difficult to ascertain. It is clear, however, that ribs were consistency cut into proximate sections with the head of the rib and medial sections. No rib ends were observed in the assemblage. Both observed scapulae were sawn at the neck, though one into a slice and the other as a large single piece. 


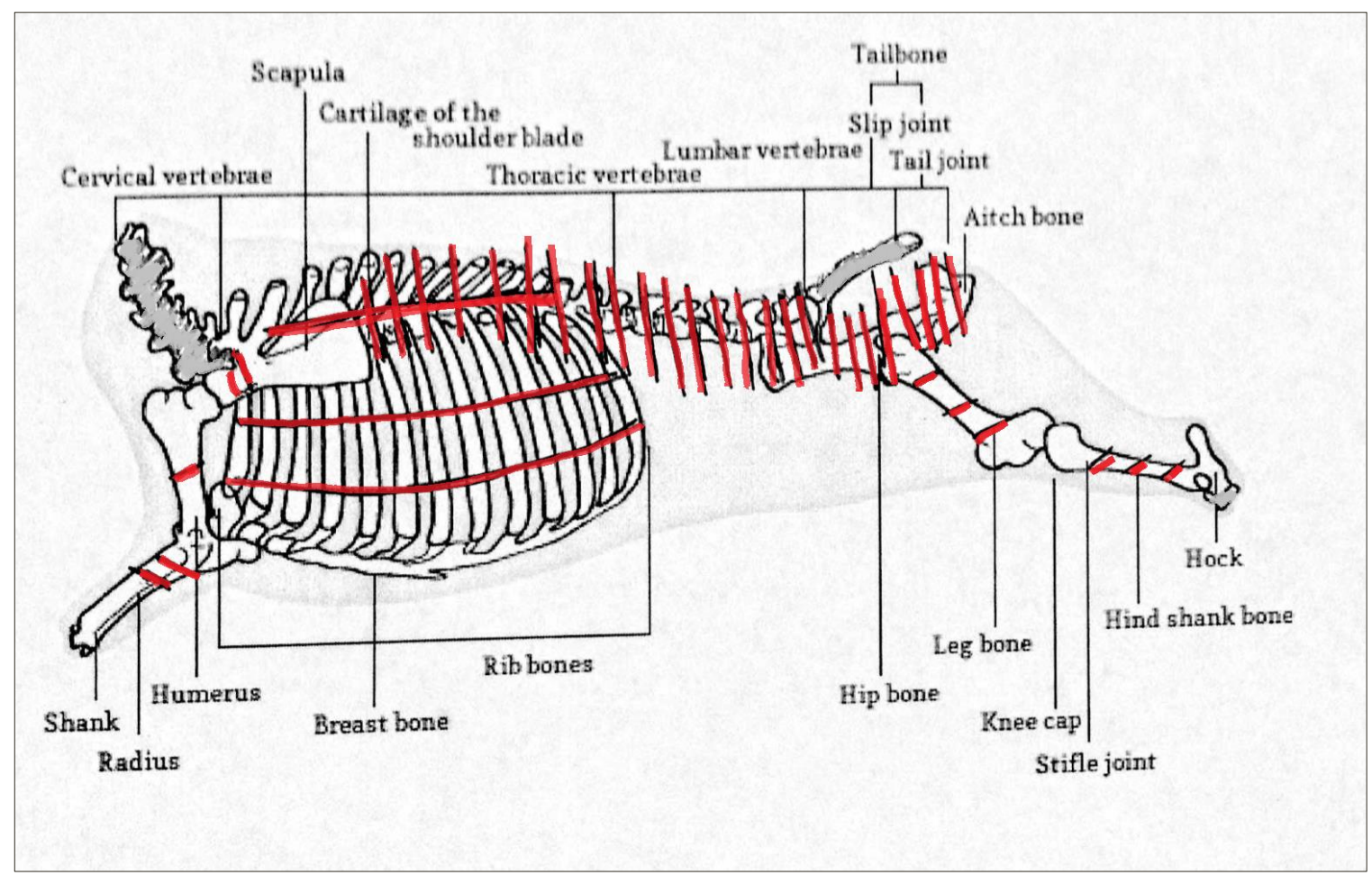

Figure 9. Beef butchering patterns. Red lines indicate areas of slicing; cervical and caudal vertebrae are greyed out as none were observed.

Although identifiable aspects of the appendicular skeleton were quite large compared to the axial elements, butchery patterns are difficult to discern due to small sample size. Numerous appendicular elements were reconstructed from multiple pieces that had broken apart either in-situ or through excavation. In the forelimb, only two humeri, one ulna, and five radii were observed. The radii were mostly cut on an angle to the bone, though one example differs. In the hind limb only eight specimens were recovered. The femur was sawn into proximal, distal, as well as medial sections. The tibia is also sawn along the shaft; no proximal nor distal pieces were recovered.

Extrapolations in butchery of other taxa are impossible to reconstruct with such little evidence, though the few cuts that are present are consistent with the cuts seen in beef. The Odocoileous vertebrae is split down the center, like the beef cuts, and as is common modern practice. The Sus os coxae specimens are cut along the superior ramus, comparable to the beef cuts. The single Sus humerus cut is not similar to the humeri cuts of beef, as it is very thin. The Ovis-Capra radius is also unlike the beef assemblage, if only because no Bos distal radii were observed; the single Ovis-Capra radius had indeterminate marks to tell what tool was used to process the bone. 


\section{DISCUSSION}

\section{Temporality}

The widespread use of electric saw in the assemblage gives some idea of temporality for the zooarchaeological assemblage from Fort Brown. The first patent for a mechanical electric saw within the US was distributed in 1917, though the first commercially available meat saws were not produced until 1930 (Dasovich and Vollman 2017). The city of Brownsville built an electric plant in 1908 (Davenport 2010). Consistency in the thickness of sawn slices also suggests electric saw usage, as the electric saw allows for more control and replicability than hand sawing. Most of the archaeological contexts from where the materials analyzed here were recovered came from outside or near the construction zones of buildings reconstructed after the hurricanes in 1919 or 1930, thereby consistent with a post-1917 date for much of the assemblage (Carlson et al. 1990).

\section{Consistency and Departure from Modern European American Butchery Techniques}

With contexts within the early to mid-twentieth century, comparison of the butchery practices at Fort Brown and modern European American butchery techniques is warranted. As Bos was the overwhelming component, and the only taxa with sufficient recovery to comment on butchery patterns, I shall only discuss consistency and departure of beef butchery.

Some aspects of beef butchery seen in the Fort Brown assemblage are strikingly similar to modern butchery practices. The splitting of the carcass down the vertebral column is an extremely common cross-cultural pattern after the slaughter and removal of the head and meatless phalanges (Seetah 2006a; Seetah et al. 2014). The slicing of lumbar vertebrae is also consistent with the creation of prized steaks, such as the T-bone or porterhouse. The treatment of the os coxae and sacrum, however, are not at all consistent with modern European American butchery practice.

Modern western foodways prefer lean, boneless meats; today butchers remove the os coxae (which has been halved into right and left through the pubic symphysis and which is referred to as the "H bone") from the rest of the rump and do not sell cuts of meat with the bone (Yeakey 2015, personal communication). From the Fort Brown assemblage, however, it seems that cuts of beef containing parts of the os coxae are common; this important distinction from current European American butchery practice is explored in terms of military and local diets, as expanded below.

\section{Consistency and Departure from Military Diets}

Food and diets are highly regulated within military environments, especially where there is communal or group dining. While rations have changed over time (Rees 1998), meat has remained one of the most important components of martial diets. The Department of War released a series of manuals for Army cooks; in 1917, the manual recommends daily rations of 20 ounces of fresh beef, which could be substituted for various other meats (Deitrick 1917). The manual outlines the 
expectations for meat procurement, sanitation, and butchering. Figures 10, 11, and 12 show butchering patterns suggested by the U.S. Army. Animal carcasses were expected to be delivered after primary butchery; the remains were killed and cleaned, with head and phalanges removed. Unfortunately, comparing the butchery suggested in the Army's manual to the butchery seen at Fort Brown is difficult as drawings and descriptions in Deitrick (1917) only concern appendicular elements, whereas the most distinctive butchering evidence seen in this assemblage was in the axial elements. Neither the descriptions nor the diagrams make any reference to chopping of the os coxae and sacral elements, instead implying that the round was to be kept whole. The available published history and available records of Fort Brown do not indicate if secondary butchery was done on camp or if the meat was bought fully butchered from Brownsville and prepared on camp. Fort Brown maintained a kitchen and dining mess, in addition to private officer quarters; enlisted men would have likely kept most of their meals in the Army-regulated dining hall, while officers could have more freedom to maintain their own dining habits.

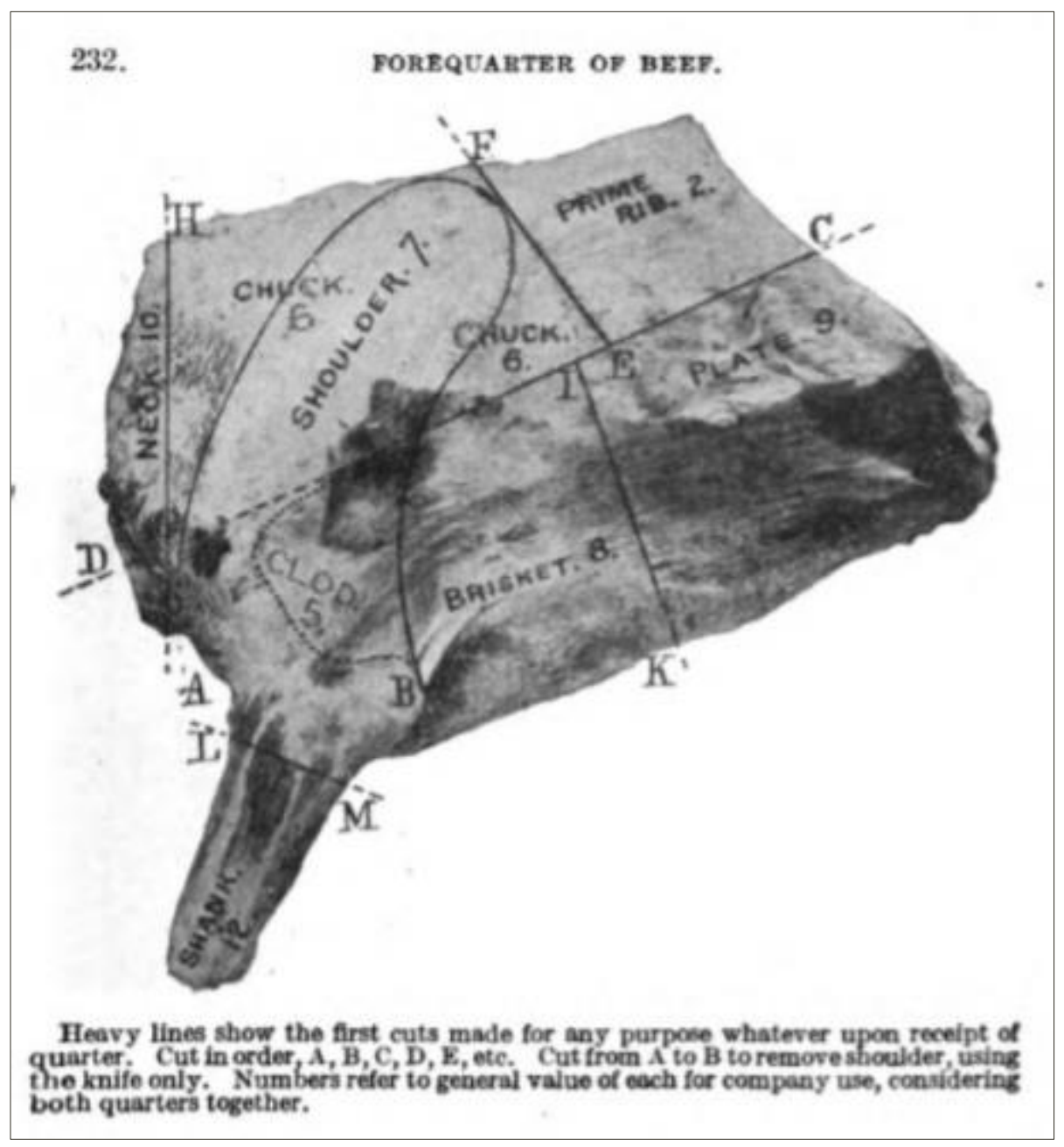

Figure 10. Suggested forequarter cuts of beef. Manual for Army Cooks, 1917: 69. 


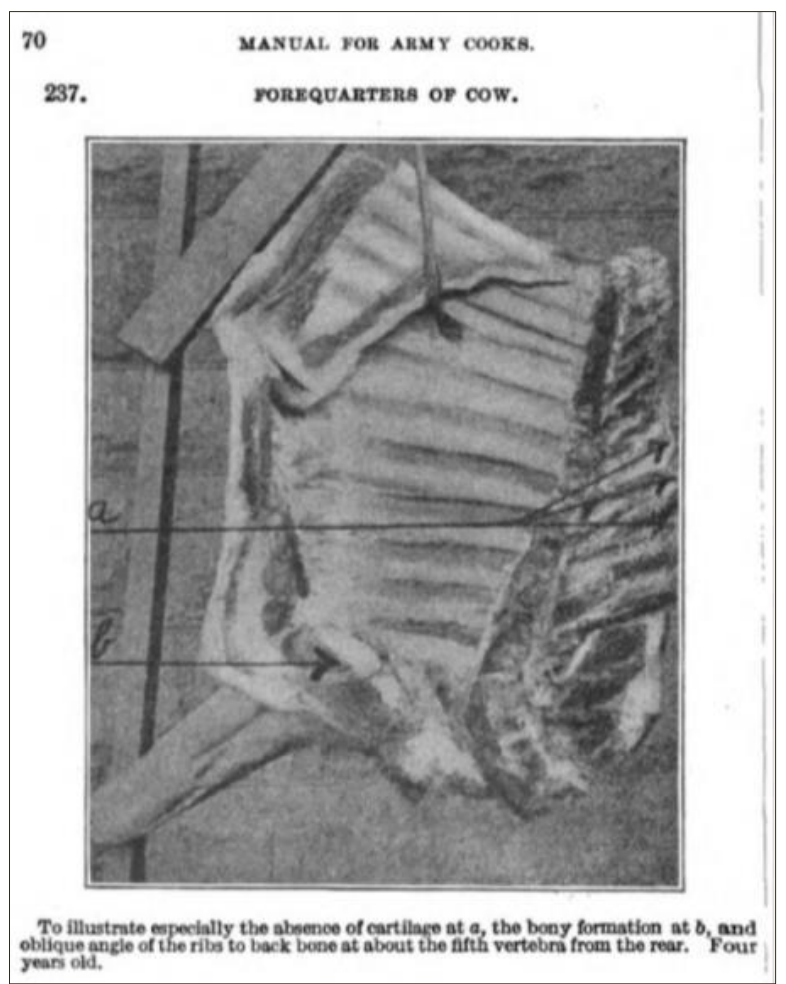

Figure 11. Suggested splitting of beef carcass. Manual for Army Cooks, 1917: 70.

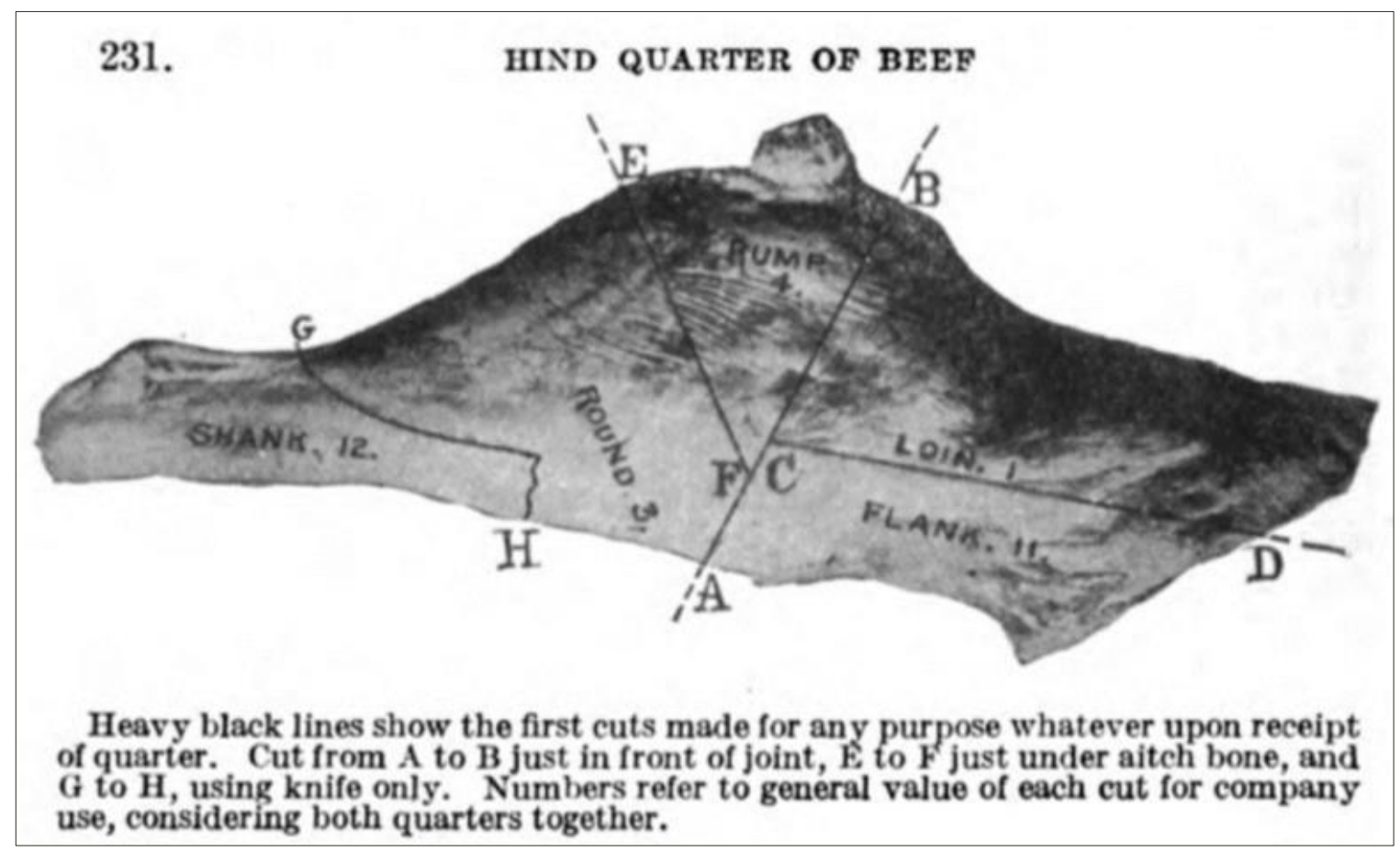

Figure 12. Suggested cuts for beef hindquarter. Manual for Army Cooks, 1917: 68. 
Comparison of the meat cuts may provide more interesting insight. Figure 13 shows the preferential selection of beef cuts by the Department of War (Deitrick 1917:61), which can be compared to Figure 6, the types of cuts seen at Fort Brown. The cuts of beef prescribed in the Army manual are not the predominate cuts seen in the Fort Brown assemblage; there is an overwhelming number of round cuts at Fort Brown, due to the abundance of os coxae and sacral elements. The assemblage almost closely resembles the suggestions for roasts, excepting the preponderance of shank (lower fore/hindlimb) cuts.

\begin{tabular}{|c|c|c|c|c|}
\hline Order. & Roasts. & Steaks. & $\begin{array}{l}\text { Bolled } \\
\text { beef. }\end{array}$ & $\begin{array}{c}\text { Corned } \\
\text { beet. }\end{array}$ \\
\hline $\begin{array}{l}1 \ldots \ldots \cdots \\
2 \ldots \ldots \cdots \\
3 \ldots \ldots \cdots \\
4 \ldots \ldots \cdots \\
6 \ldots \ldots \cdots \\
7 \ldots \ldots \cdots\end{array}$ & 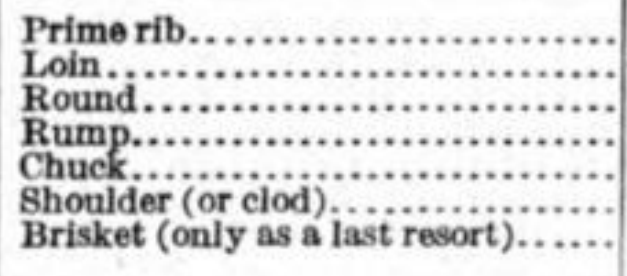 & $\begin{array}{l}\text { Loin......... } \\
\text { Round...... } \\
\text { Prime rib... } \\
\text { Rump....... } \\
\text { Clod......... } \\
\text { Chuck...... } \\
\text { Shoulder.... }\end{array}$ & $\begin{array}{l}\text { Shoulder.. } \\
\text { Brisket.... } \\
\text { Plate...... } \\
\text { Flank..... } \\
\text { Shank..... } \\
\text { Neck...... }\end{array}$ & $\begin{array}{l}\text { Brisket. } \\
\text { Plate. } \\
\text { Flank. } \\
\text { Rump. } \\
\text { Shoulder. }\end{array}$ \\
\hline
\end{tabular}

Figure 13. Suggested selection of beef cuts. Manual for Army Cooks, 1917: 65.

The manual implies that the entire animal was prepared to be used; cuts of meat and bone that were not used for primary steaks or roasts (such as prime rib or loin) were to be used as stew meat, which was a daily fixture of the army diet. Meat for stew is suggested to be cut into half to full inch cubes; broiled meat is advised to be cut into slices one inch thick, but as large as desired (Deitrick 1917:132). The preponderance of sliced meat cuts at Fort Brown suggests that beef was prepared for stews; the average thickness of the sliced bone was just under one inch (a difference of $9 \mathrm{~mm}$ from the average recorded at Fort Brown). Stews were likely prepared at Fort Brown according to the Department of War recommendations; however, the cuts of beef used in the stews were not the recommended cuts.

\section{Consistency and Departure from Tejano/Mexican Diets}

In early twentieth century Brownsville, cattle were slaughtered and butchered at the city market downtown. A promotional booklet from the late nineteenth century (Chatfield 1893) relates that the city slaughter pen would change $\$ 1$.00US for the primary butchery of beef, which was four times the rate to slaughter sheep or goats. Chatfield (1893) explains that butchers worked within the city market and were primarily of Mexican descent, and the Mexican dollar was used as the primary currency to buy meat, which was approximately worth $65 \%$ of US currency at the time. Meat was bought per the 
pound; Table 3 presents the prices that Chatfield lists. At the turn of the twentieth century, Chatfield relates that approximately half of Brownsville's 7,000 residents were Mexicans. The Mexican influence is seen in the diet of past and present Brownsville residents and may have crossed into the military diet of Fort Brown through butchered meat. The cuts of large pieces of meat, such as those represented in the Fort Brown assemblage (note the scales for specimens in Figures 1 and 2), are often seen in Mexican soups, such as Caldo de Res or Carne guisada; as mentioned above, stews and soups would have been well supported by the Department of War to meet ration quotas. Meat foodways at Fort Brown, perhaps supplied by local butchers, likely reflected local Mexican-American preparation techniques and flavors.

Table 3. Price of various cuts of meat, from Chatfield (1893).

\begin{tabular}{ll}
\hline Cut of Meat & Mexican cents per pound \\
\hline Rough cut & 04 \\
Round steak & 06 \\
Beef roast & 07 \\
Sirloin & 07 \\
Porterhouse & 07 \\
Tenderloin & 08 \\
Pork Roast & 10 \\
Pork chop & 10 \\
Mutton & 08 \\
Pork sausage & 18 \\
Beef tongue & $18-25$ \\
Venison & 05 \\
\hline
\end{tabular}

\section{CONCLUSIONS}

Butchery patterns within the Fort Brown faunal assemblage diverge from both modern European American butchery practices and early twentieth century military guidelines in the butchery and consumption of beef os coxae. The majority of butchery marks were made with an electric saw, indicating that the remains are post-1917, cuts of bone (and assumedly meat) from less desirable parts of cattle indicate frugal choices by Fort Brown cooks. The large slices of meat and bone, particularly from non-steak bearing regions such as the os coxae and the appendicular elements, suggest the use of stews and soups as an integral part of Fort Brown's foodways. While interpreting food patterns across ethnic, class, or gender divisions using zooarchaeological remains can be difficult (Crabtree 1990; Gifford-Gonzalez 1991, 1993; Huelsbeck 1991; Reitz 1987; Reitz et al. 2006; Seetah 2006a; Seetah et al. 2014; Twiss 2012), it is clear that there are Mexican influences on border diets.

The departure of the butchery trends at Fort Brown from published and dominant European American patterns speak to the importance of archaeological investigation within historical contexts. Fort Brown and Brownsville were and are truly multi-cultural places, where Tejano, Mexican, European American, and African American influences have met, conflicted, merged, and evolved over the years. Foodways can be useful lenses for understanding cultural differences and change in multi-cultural spaces (Crabtree 1990; Dawdy 2010; Gifford-Gonzalez 1993; Landon 1996; Twiss 
2012) and archaeological investigation can allow for narratives and understandings of peoples underrepresented within the historical record (Deetz 1996). Further archival and archaeological investigation may be able to reveal even greater detail about the dietary choices, patterns, and sociocultural influences experienced at Fort Brown.

\section{ACKNOWLEDGEMENTS}

I would like to thank the Anthropology Research Laboratory, and particularly Elanor Sonderman, for access to the materials from Fort Brown. This work would have been impossible without the use of the faunal comparative collections from the Department of Anthropology at Texas A\&M University; many thanks to Dr. Darryl de Ruiter for access to and assistance with these collections. The Cushing Memorial Library provided access to some of the historical documents utilized in this paper and individuals from the Brownsville Historical Society helped to provide historical context. Thanks to Kelly Graf for use of the digital calipers. This paper was much improved by the thoughtful comments of reviewers and the great editors of JTAH, of which I am very grateful; all persisting errors are my own.

\section{REFERENCES CIED}

Andahl, R.O.

1978 The Examination of Saw Marks. Journal of the Forensic Science Society 18(1): 31-46.

Bunn, Henry T, and Ellen M Kroll

1986 Systematic Butchery by Plio/Pleistocene Hominids at Olduvai Gorge, Tanzania. Current Anthropology: 431-452.

Carlson, Shawn Bonath, Joe Saunders, Frank Winchell, and Bruce Aiken

1990 Archaeological Investigations at Fort Brown (41CF96), Cameron County, Texas. Unpublished Reports of Investigations. Archaeological Research Laboratory Texas A\&M University, College Station, TX.

Chatfield, W.H.

1893 The Twin Cities of the Border and the County of the Lower Rio Grand: Brownsville, Texas and Matamoros, Mexico. E.P. Brandao, New Orleans.

Christian, Garna L.

1989 The Brownsville Raid's 168th Man: The Court-Martial of Corporal Knowles. The Southwestern Historical Quarterly 93(1): 45-59.

Crabtree, Pam J.

1985 Historic Zooarchaeology: Some Methodological Considerations. Historical Archaeology 19(1): 76-78. 
1990 Zooarchaeology and Complex Societies: Some Uses of Faunal Analysis for the Study of Trade, Social Status, and Ethnicity. Archaeological Method and Theory 2: 155-205.

Dasovich, Steve J., and Gwyneth J. Vollman

2017 Human or Machine? An Analysis of Saw Marks on Animal Bones from Two Sites in St. Charles, MO. Society for Historical Archaeology 50th Annual Conference on Historical and Underwater Archaeology. Fort Worth, TX.

Davenport, Elizabeth P

2010 Fort Brown. Handbook of Texas Online. Texas State Historical Association. http://www.tshaonline.org/handbook/online/articles/qbf07, accessed 6 June 2017.

Dawdy, Shannon Lee

2010 "A Wild Taste": Food and Colonialism in Eighteenth- Century Louisiana. Ethnohistory 57(3): $389-414$.

Deetz, James

1996 In Small Things Forgotten: The Archaeology of Early American Life. Anchor Books.

Deitrick, Leonard Lyon

1917 Manual for army cooks. War Department, Office of the Quartermaster General. Government Printing Office, Washington. http://babel.hathitrust.org/cgi/pt?id=uiug.30112117719663;view=1up;seq=6, accessed 6 June 2017.

Domínguez-Rodrigo, M., S. de Juana, A.B. Galán, and M. Rodríguez

2009 A new protocol to differentiate trampling marks from butchery cut marks. Journal of Archaeological Science 36(12): 2643-2654.

Domínguez-Rodrigo, Manuel, Travis Rayne Pickering, and Henry T Bunn

2010 Configurational approach to identifying the earliest hominin butchers. Proceedings of the National Academy of Sciences 107(49): 20929-20934.

Freas, Laurel E.

2010 Assessment of Wear-Related Features of the Kerf Wall from Saw Marks in Bone. Journal of Forensic Sciences 55(6): 1561-1569.

Gifford-Gonzalez, Diane

1991 Bones are not enough: Analogues, knowledge, and interpretive strategies in zooarchaeology. Journal of Anthropological Archaeology 10(3): 215-254.

1993 Gaps in zooarchaeological analyses of butchery: Is gender an issue. In From Bones to Behavior: Ethnoarchaeological and Experimental Contributions to the Interpretation of Faunal Remains, pp. 181-200. Occasional Paper 21. Center for Archaeological Investigations, Carbondale, IL. 
Greenfield, Haskel J.

2006 Slicing Cut Marks on Animal Bones: Diagnostics for Identifying Stone Tool Type and Raw Material. Journal of Field Archaeology 31(2): 147-163.

Huelsbeck, David R.

1991 Faunal Remains and Consumer Behavior: What Is Being Measured? Historical Archaeology 25(2): 62-76.

Jolley, Robert L.

1983 North American Historic Sites Zooarchaeology. Historical Archaeology 17(2): 64-79.

Koon, H.E.C., T.P. O'Connor, and M.J. Collins

2010 Sorting the butchered from the boiled. Journal of Archaeological Science 37(1): 62-69.

Landon, David B.

1996 Feeding Colonial Boston: A Zooarchaeological Study. Historical Archaeology 30(1): i-153.

2005 Zooarchaeology and Historical Archaeology: Progress and Prospects. Journal of Archaeological Method and Theory 12(1): 1-36.

Landon, David B.

2009 An Update on Zooarchaeology and Historical Archaeology: Progress and Prospects. In International Handbook of Historical Archaeology, edited by David Gaimster and Teresita Majewski, pp. 77-104. Springer, New York.

Lyman, R. Lee

1977 Analysis of Historic Faunal Remains. Historical Archaeology 11: 67-73.

1987a Archaeofaunas and Butchery Studies: A Taphonomic Perspective. Advances in Archaeological Method and Theory 10: 249-337.

1987b On Zooarchaeological Measures of Socioeconomic Position and Cost-Efficient Meat Purchases. Historical Archaeology 21(1): 58-66.

Marcum, Richard Tandy

1964 Fort Brown, Texas: History of a Border Post. Unpublished Ph.D. Dissertation, Texas Technological College, Lubbock, Texas.

Rees, John U

1998 The Foundation of an Army is the Belly: North American Soldiers' Food, 1756-1945. ALHFAM Proceedings of the 1998 Conference and Annual Meeting, 21:pp. 49-64. http://www.revwar75.com/library/rees/belly.htm, accessed 6 December 2015. 
Reitz, Elizabeth J.

1987 Vertebrate Fauna and Socioeconomic Status. In Consumer Choice in Historical Archaeology, edited by Suzanne M. Spencer-Wood, pp. 101-119. Springer US.

Reitz, Elizabeth J., Barbara L. Ruff, and Martha A. Zierden

2006 Pigs in Charleston, South Carolina: Using Specimen Counts to Consider Status. Historical Archaeology 40(4): 104-124.

Rixson, D

1989 Butchery evidence on animal bones. Circaea 6(1): 49-62.

Saville, P.A., S.V. Hainsworth, and G.N. Rutty

2007 Cutting crime: the analysis of the "uniqueness" of saw marks on bone. International Journal of Legal Medicine 121(5): 349-357.

Seetah, Krish

2006a Butchery as an analytical tool: a comparative study of the Romano-British and Medieval periods. Unpublished Ph.D. Dissertation, University of Cambridge, Cambridge, UK.

2006b The importance of cut placement and implement signatures to butchery interpretation. ICAZ Essay Prize Submission.

2008 Modern analogy, cultural theory and experimental replication: a merging point at the cutting edge of archaeology. World Archaeology 40(1): 135-150.

Seetah, Krish, Aleksander Pluskowski, Daniel Makowiecki, and Linas Daugnora

2014 New technology or adaptation at the frontier? Butchery as a signifier of cultural transitions in the medieval Eastern Baltic. Archaeologia Baltica 20: 59-76.

Shaffer, Brian S.

1990 Analysis of the Faunal Remains. In Archaeological Investigations at Fort Brown (41CF96) Cameron County, Texas, edited by Shawn Bonath Carlson, Joe Saunders, Frank Winchell, and Bruce Aiken, pp. 135-146. Reports of Investigations No. 11. Archaeological Research Laboratory Texas A\&M University.

Sides, Joseph C.

1942 Fort Brown Historical: History of Fort Brown, Texas Border Post on the Rio Grande. The Naylor Company, San Antonio, TX.

Twiss, Katheryn

2012 The Archaeology of Food and Social Diversity. Journal of Archaeological Research 20(4): 357395.

Yeakey, Bill

2015 Butcher for over 30 years. Personal Communication. 